\title{
Effect of cigarette smoking on gastric emptying
}

\author{
DAVID S GRIMES, JOHN GODDARD
}

British Medical fournal, 1978, 2, 460-461

\section{Summary and conclusions}

Gastric emptying after a test meal was studied in 17 normal volunteers-10 habitual smokers and seven non-smokers. The solid component of the test meal was labelled with technetium and the liquid component with indium. After one meal the habitual smokers smoked two cigarettes. Emptying curves were produced for both technetium and indium, and the differences between curves for meals with and without cigarettes were analysed.

Cigarette smoking accelerated the rate at which the liquid component of a meal left the stomach. This may be important in the pathogenesis of duodenal ulcer and the delay in healing caused by cigarette smoking.

\section{Introduction}

Cigarette smoking may be important in the pathogenesis of duodenal ulcer and appears to delay healing. ${ }^{1}$ The intermediary mechanism, however, is not clear. The concept that the rate of gastric emptying tends to be more rapid than normal in patients with duodenal ulcer ${ }^{23}$ is controversial ${ }^{4}{ }^{5}$; if true, this phenomenon may be either a cause or effect of the disease. We think it is probably causative, and a rapid rate of gastric emptying may be an important factor in the pathogenesis of duodenal ulcer. ${ }^{6}$ Because of this we investigated the effect of cigarette smoking on gastric emptying in normal subjects. We thought that cigarette smoking and duodenal ulcer might be linked, in which case smoking a cigarette would probably accelerate gastric emptying. By using radioactive tracer techniques that had recently become available ${ }^{5-7}$ we were able to measure simultaneously the rates at which the solid and liquid components of a meal left the stomach.

\section{Subjects and methods}

We studied ten normal subjects who were habitual smokers. All were men aged 20-30 years. Each volunteer ate two test meals in randomised sequence at an interval of one week. Both meals consisted of Readybrek and milk, but immediately after one the volunteer smoked two cigarettes. We also studied seven normal volunteers who did not smoke: they each received one test meal. The solid componen of the test meal was $30 \mathrm{~g}$ of Readybrek, which was labelled with $0.1 \mathrm{mCi}$ of ${ }^{90 \mathrm{~m} T c}$-sulphur colloid and mixed with $200 \mathrm{ml}$ of warm milk. After the meal the volunteer drank a further $200 \mathrm{ml}$ of milk, to which we added $0.1 \mathrm{mCi}$ of ${ }^{113 \mathrm{~m} I n-d i e t h y l e n e}$ triamine penta-acetic acid (DTPA).

For one hour after each meal the upper abdomen of the recumbent subject was viewed by a gamma-camera, which was linked to an on-

Royal Infirmary, Blackburn, Lancashire BB2 3LR DAVID S GRIMES, MB, MRCP, consultant physician

Department of Medical Biophysics, University of Manchester, Manchester M13

JOHN GODDARD, PHD, lecturer (present address: Department of Nuclear Medicine and Medical Biophysics, Vanderbilt University, Nashville, Tennessee, USA) line computer (Med 11, Nuclear Data Inc). Successive five-minute images were accumulated for the peak energies of both ${ }^{113 \mathrm{~m} I n}$ and $\bar{O}$ ${ }^{99 \mathrm{~m} T \mathrm{Tc}}$ and saved on a magnetic disc. At the end of each study the $\overline{0}$ gastric image was delineated on a screen with a light-pen, and the $\bar{\omega}$ total counts within this area on each of the 12 images were calculated $\bar{\nabla}$ by the computer. Emptying curves for both technetium and indium were produced by adjusting the initial counts for radioactive decay, क and the technetium curve was further corrected for indium cross-talk $\vec{\theta}$ (the proportion of indium counts detected in the technetium channel). The emptying curves were subsequently normalised to one-that is, $\vec{\omega}$ all points on each curve were expressed as a fraction of the maximum. OT

Previous investigation had indicated that ${ }^{113}$ In-DTPA is an imperfect marker of the liquid phase since an appreciable proportion of the $113 \mathrm{~m}$ In appears to adsorb on to the solid component of the meal. This "fractional adsorption" must be determined by in-vitro studies, $\frac{\vec{\omega}}{\omega}$ and we used the following method. We incubated $5 \mathrm{~g}$ of Readybrek 0 at $37^{\circ} \mathrm{C}$ for 30 minutes with $20 \mathrm{ml}$ of $0.05 \mathrm{~N} \mathrm{HCl}$ and $10 \mathrm{ml}$ of milk to which had been added $0.02 \mathrm{mCi}$ of ${ }^{113 \mathrm{~m} I n-D T P A}$. The mixture 8 was centrifuged at $6500 \mathrm{rpm}$ for five minutes, and the relative counts $\mathrm{O}$ of the supernatant and sediment were measured. The counts of trapped or absorbed liquid were subtracted from the total counts of $\vec{N}$ the sediment to estimate the fractions of the total ${ }^{113 \mathrm{~m} I n}$ counts that were adsorbed to the solid. The suitability of $99 \mathrm{mTc}$-sulphur colloid was similarly determined, the fractions of the total ${ }^{99 \mathrm{mT}} \mathrm{Tc}$ counts that were adsorbed to the solid being measured.

\section{Results}

In-vitro studies showed that $99 \%$ of the $99 \mathrm{mTc}$-sulphur colloid label was adsorbed to the solid component of the meal (mean fractional adsorption $0.99 \pm S D 0.007 ; n=14$ ). This label was thus an excellent marker of the solid phase of this test meal. Similar studies showed that the mean fractional adsorption of $113 \mathrm{mIn}$ to the solid was $0 \cdot 196 \pm$ SD $0.166(n=24)$, confirming that $113 \mathrm{~m}$ In-DTPA was an imperfect marker of the liquid phase. To obtain a true liquid emptying

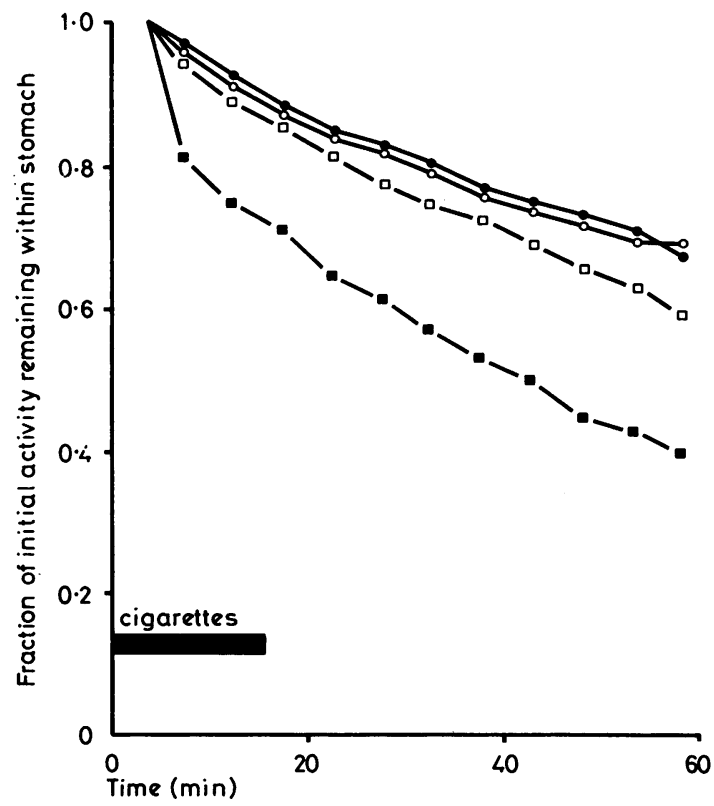

FIG 1-Gastric emptying expressed as fraction of initial counts remaining over gastric area at successive fiveminute intervals.

$O=$ Solid phase, control meal. $O=$ Solid phase, with cigarettes. $\square=$ Liquid phase, control meal. $\square=$ Liquid phase, with cigarettes. 
curve we subtracted from each point on the normalised indium curve the proportion of the solid phase that was labelled with ${ }^{113 m}$ In. The normalised indium curves were corrected by the equation $\operatorname{In}^{*}(t)=$ $\operatorname{In}(t)-(a \times \operatorname{Tc}(t))$, where $\operatorname{In} *(t), \operatorname{In}(t)$, and $T c(t)$ represent the normalised values of the points on the corrected and uncorrected indium curves and the technetium curve respectively at time $t$ and where a is the fractional adsorption of $113 \mathrm{~m}$ In to solid.

The points on the corrected emptying curves (fig 1) were analysed by the Wilcoxon matched-pairs signed-ranks test, and a probability of $\mathbf{P}<0.05$ was taken to indicate a significant difference (the first points were not analysed as they were normalised to one). There were no significant differences between points on the curves representing solid-phase emptying with and without cigarettes. Gastric emptying of the liquid phase, however, was more rapid when cigarettes were smoked, and all points on the curves were significantly different. Points on the curves recording solid- and liquid-phase emptying without cigarette smoking were compared with corresponding points on curves obtained for the six volunteers who did not smoke. For clarity these curves are not shown in fig 1 , but on analysis with the Mann-Whitney $U$ test there were no significant differences.

Each curve is described mathematically by the expression $(1-f(t)) / A$, where $f(t)$ is the fraction of isotope remaining at the end of the study and $\mathrm{A}$ the area under the emptying curve. The expression, whose derivation is described in detail elsewhere, ${ }^{6}$ is called the "emptying index." For a curve normalised to one this index is a number between 0 and 1 that is directly proportional to the overall rate of emptying and the motility of the stomach. We calculated the emptying indices for all curves. Fig 2 shows the values for the volunteers who were habitual smokers. The points were compared by the Wilcoxon matched-paired signed-rank test. There was no difference between the emptying indices of the solid-phase curves with and without cigarettes, but the values for the liquid-phase curves were significantly greater when cigarettes were smoked $(T=5, n=10, P<0.02)$.

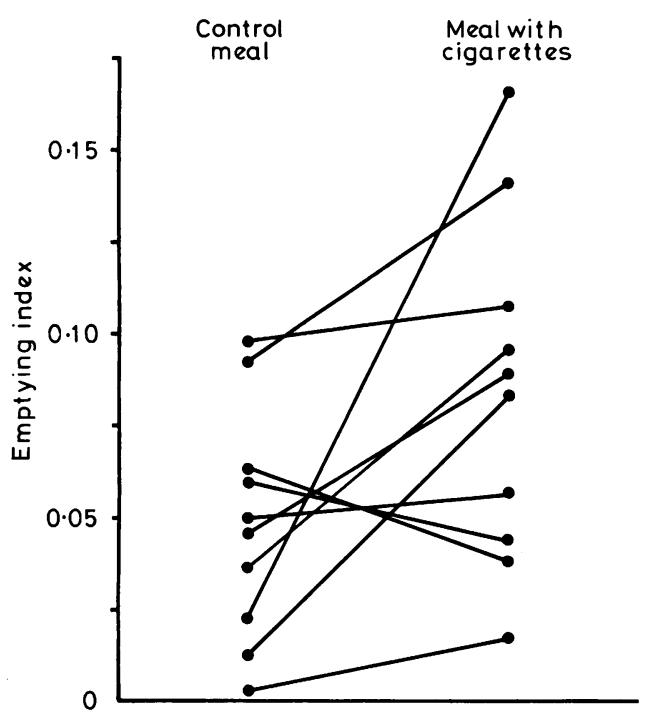

FIG 2-Gastric emptying of liquid phase for smokers after control meal and meal with cigarettes, expressed as emptying index.

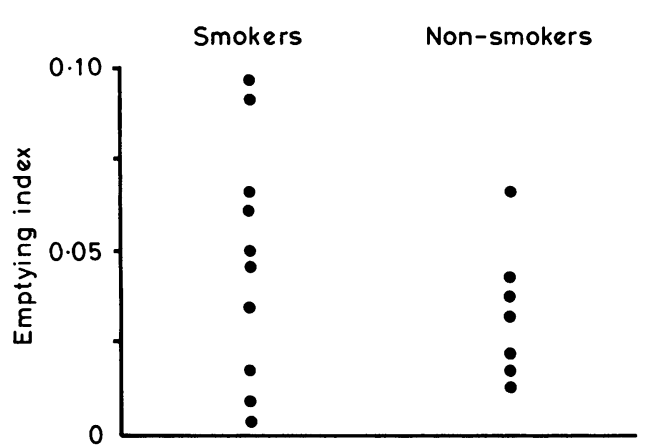

FIG 3-Gastric emptying of liquid phase expressed as emptying index for habitual smokers and non-smokers.
Figure 3 shows the emptying indices for solid- and liquid-phase emptying curves for habitual smokers when not smoking and nonsmokers. On analysis with the Mann-Whitney $U$ test there were no significant differences.

\section{Discussion}

The patterns of gastric emptying found in the present study (fig 1) were similar to those in other studies ${ }^{5} 6$ since during the investigation liquid left the stomach exponentially and solid in a linear fashion. Our results show that smoking a cigarette increases the rate at which liquid leaves the stomach. This suggests that the rate of acidification of the duodenum after a meal might be correspondingly more rapid, especially as solid does not appear to accompany and therefore presumably does not buffer the excess liquid leaving the stomach. It could be argued that an initial rapid washout of liquid from the stomach would result in only dilute acid entering the duodenum and that hydrogen ion concentration, is more important than hydrogen ion load in the pathogenesis of duodenal ulcer. If the initial acid load leaving the stomach is dilute, however, then the later acid load, although smaller in volume, will be more concentrated. ${ }^{3}$ However this is viewed, if the liquid phase of the gastric contents passes rapidly into the duodenum an environment favourable to the development of duodenal ulcer will probably result.

Our results do not indicate the mechanism by which smoking a cigarette after a meal accelerates emptying of the stomach. For a given pyloric resistance cigarette smoking apparently stimulates gastric motility. Alternatively, relaxation of the pylorus might allow more rapid gastric emptying, gastric motility remaining constant. Although both mechanisms might co-exist, the second explanation is supported by the observation of Read and Grech ${ }^{8}$ that cigarette smoking induced pyloric reflux, which was assumed to be a direct result of pyloric relaxation and might be important in the pathogenesis of gastric ulcer. Other workers have also found that cigarette smoking affects gastric physiology in ways that may be considered to be detrimental. Stancin and Bennett ${ }^{9}$ and Chattopadhyay et $a^{10}$ showed that cigarette smoking relaxed the lower oesophageal sphincter to allow gastro-oesophageal reflux.

Interestingly, the effects of cigarette smoking on gastric emptying are similar to those of substituting white for wholemeal bread, ${ }^{6}$ a process that has also been considered to be important in the pathogenesis of duodenal ulcer. ${ }^{11}$ Furthermore, some antacids delay gastric emptying, ${ }^{12}$ and as the antacid potency of antacids is probably not closely related to their ability to relieve dyspeptic symptoms ${ }^{13}$ this may be a way in which they exert an appreciable proportion of their therapeutic benefit. The rate at which the stomach empties may be more important than is generally thought.

We thank all the volunteers who took part in this study, and Miss Anne Marie McNeilly for technical assistance.

Requests for reprints should be addressed to Dr D S Grimes.

\section{References}

${ }^{1}$ Doll, R, Jones, F A, and Pygott, F, Lancet, 1958, 1, 657.

2 Griffin, G H, et al, Gastroenterology, 1968, 54, 1 .

${ }^{3}$ George, J D, American fournal of Digestive Diseases, 1968, 13, 376

4 Cobb, J S, et al, American fournal of Digestive Diseases, 1971, 16, 207.

${ }^{5}$ Heading, R C, et al, Gastroenterology, 1976, 71, 45.

${ }^{6}$ Grimes, D S, and Goddard, J, Gut, 1977, 18, 725.

7 Harvey, R F, et al, Lancet, 1970, 1, 16.

${ }^{8}$ Read, N W, and Grech, P, British Medical fournal, 1973, 3, 313.

9 Stancin, C, and Bennett, J R, British Medical fournal, 1972, 3, 793.

${ }^{10}$ Chattopadhyay, D K, Greaney, M G, and Irvin, T T, Gut, 1977, 18, 833.

11 Cleave, T L, Peptic Ulcer. Bristol, Wright, 1962

12 Hurwitz, A, et al, Gastroenterology, 1976, 71, 268.

13 Fordtran, J S, Morawski, S G, and Richardson, C J, New England fournal of Medicine, 1973, 288, 923.

(Accepted 2 fune 1978) 